\title{
Wax deposition process: mechanisms, affecting factors and mitigation methods
}

\begin{abstract}
Crude oil transportation in the pipelines of the cold environment is affected by the low temperature causing a problem such as wax deposition. The flow assurance in the hydrocarbon pipelines is very important due to the precipitation of the solid phase of wax on the pipe wall creating pressure abnormalities and causing an artificial blockage leading to a reduction or interruption in the production. Wax can precipitate as a solid phase on the pipe wall when its temperature (inlet coolant temperature) drops below the wax appearance temperature (WAT). In this review, wax deposition process is discussed. Also, proposed wax deposition mechanisms are outlined including molecular diffusion, shear dispersion, Brownian diffusion and gravity settling. Furthermore, the factors affecting the wax deposition process are explained, such as pipe wall temperature (inlet coolant temperature), crude oil composition, crude oil temperature, ambient temperature, flow rate, thermal history, time and pressure. There are several mitigation methods were used in the different oil fields around the world to reduce wax deposition such as pigging, inhibitors and thermal insulation.
\end{abstract}

Volume 2 Issue 2 - 2018

\author{
Muhammad Ali Theyab \\ Ministry of Higher Education and Scientific Research of Iraq
}

Correspondence: Muhammad Ali Theyab, Ministry of Higher Education and Scientific Research of Iraq, Email theyabm@Isbu.ac.uk

Received: January 10,2018 | Published: March 12, 2018
Abbreviations: WAT, wax appearance temperature; PPD, pour point depressants

\section{Introduction}

The current work is a study of wax deposition, a phenomenon that is one of the main flow assurance problems faced by the oil industry, affecting numerous oil companies around the world. Wax deposition can result in the restriction of crude oil flow in the pipeline, creating pressure abnormalities and causing an artificial blockage leading to a reduction or interruption in the production. However, in an extreme case, this can cause a pipeline or production facility to be abandoned. The wax deposition also leads to formation damage near the wellbore, reduction in permeability, changes in the reservoir fluid composition and fluid rheology due to phase separation as wax solid precipitates. One of the important issues to be noted is that the wax deposit is not solid wax, but a gel that consists of solid wax crystals and trapped liquid. The deposit is also known to harden with time in a process termed aging. ${ }^{1,2}$ The precipitation of wax components out of the oil is responsible for changes in the waxy crude oil properties, including the gelation of oil and an increase in viscosity. ${ }^{3}$ Wax contains a high molecular weight $n$-Paraffin and consists of long chain alkanes with 20 to 50 carbon atoms. ${ }^{4}$ Wax can precipitate as a solid phase when the crude oil temperature drops below the wax appearance temperature (WAT): the temperature at which the first wax crystals start to form in the crude oil in a cooling process. ${ }^{5-7}$ Wax can precipitate and arises when paraffin components in crude oil precipitate and deposit on the cold pipeline wall when the inner wall temperature (inlet coolant temperature) drops below the wax appearance temperature.

The main factor that affects the wax deposition process is the low temperature, which means that subsea pipelines are especially vulnerable. Therefore, wax deposition prevention becomes very important in deep- water oil production. Wax deposition in crude oil production systems can be reduced or prevented by one or combination of chemical, mechanical, and thermal remediation methods. However, with the advent of extremely deep production, offshore drilling and ocean floor completions, the use mechanical and thermal remediation methods becomes prohibitive economically, as a result, use of chemical additives as wax deposition inhibitors is becoming more prevalent. ${ }^{8}$ The thermal methods include heat retention, active heating such as thermal insulations, bottom hole heaters, hot oil circulation and steam circulation. The mechanical removal method includes running scrappers in the borehole and pigging in pipelines at an intervention frequency. The chemical inhibitors include pour point depressants (PPD), crystal modifiers, dispersants and solvents. Occasionally in the literature wax deposition is referred to interchangeably with wax precipitation, but the two are in fact different concepts. ${ }^{3}$ Wax deposition refers to the formation of a layer of separate solid phase and the eventual growth of this layer on a surface in contact with the crude oil. Wax deposits can be formed from an already precipitated solid phase (wax) through mechanisms of shear dispersion, gravity settling and Brownian motion, or from dissolved wax molecules through a molecular diffusion mechanism. ${ }^{9}$

The precipitated wax molecules near the pipe wall start to form an incipient gel at the cold surface. The incipient gel formed at the pipe wall is a 3-D network structure of wax crystals and contains a significant amount of oil trapped within it. The incipient gel grows as time progresses and there are radial thermal and mass transfer gradients as a result of heat loss to the surrounding area, as shown in Figure $1{ }^{6}$ This work describe several factors that affect and control the wax deposition process in pipelines, such as pipe wall temperature (inlet coolant temperature), crude oil composition, crude oil temperature, ambient temperature, flow rate, thermal history, time and pressure. Where, wax deposition increases with an increase in the temperature difference between the bulk of the wax solution and the cold surface of the pipe) ${ }^{10}$ It is occur when the surface temperature is below both the solution temperature and the solution cloud point. Alternatively, ${ }^{11}$ stated that the crude oil composition is one of the main factors that significantly impacts wax deposition nd is responsible for the pour point and viscosity reduction. The composition of crude oil comprises a mixture of molecules of different natures, there are light molecules 
like methane that are responsible for solid hydrate formation at high pressure and low temperature and heavy molecules such as long linear alkanes and isoparaffins that tend to change phase at low temperature in the phase of both macro and microcrystalline solids.

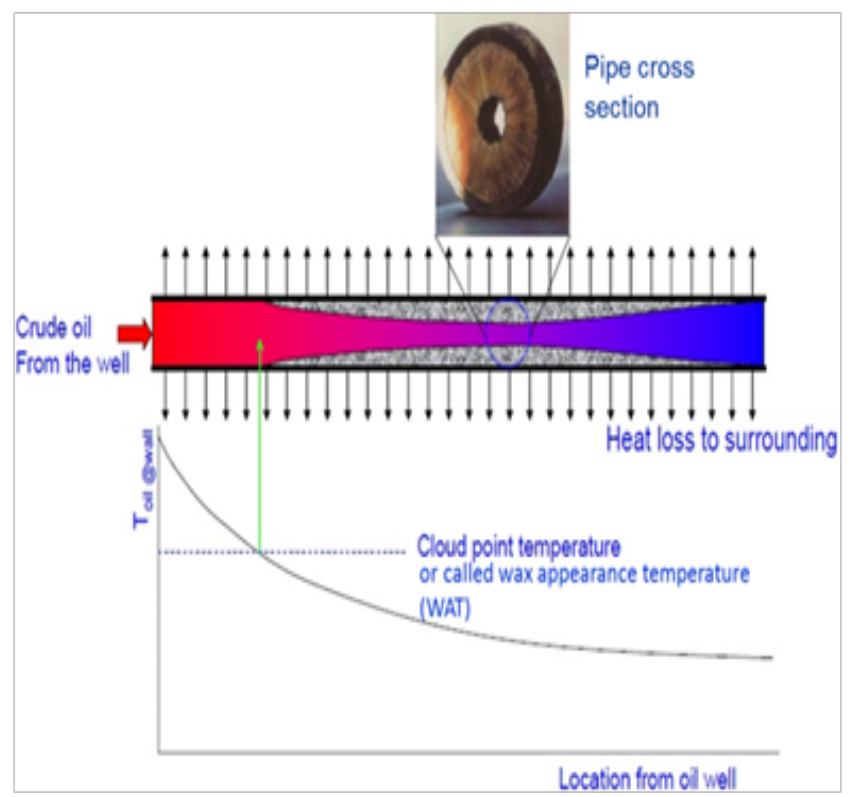

Figure I Wax deposition process in the hydrocarbon pipeline. ${ }^{46}$

Furthermore, the experimental time is considered to be one of the important factors that influence wax deposition inside the pipelines, where wax deposition increased by increasing the operation time, ${ }^{12-17}$ due to more and more paraffin being deposited from the fresh crude oil on the hydrocarbon pipeline, providing a greater opportunity for deposition upon the cold surface. ${ }^{15}$ On another hand, wax deposition increases with decreasing flow rate. This can be explained by the availability of more particles for deposition at the surface. As the flow rate increases to turbulent regimes, wax deposition decreases because shear dispersion increases. Thus, wax deposition gradually decreases as turbulence and flow rate increases. Moreover, the pressure drops during oil production from the reservoir to the surface facilities. Lighter hydrocarbons in the reservoir tend to be the first to leave the reservoir as the pressure falls; hence, the solubility of the wax is reduced. The WAT increases with the pressure above the bubble point pressure, for a constant composition. This phenomenon implies that an increase in the pressure in the single-phase liquid region (above the bubble point pressure) will aggravate wax deposition. It is evident that during deposition, wax crystals adhere to the pipe surface; so wax deposition can also be a function of surface properties. As the paraffin wax is deposited on a surface, it is held in place by adsorption forces. These adsorption forces are dependent on the free surface energy of both the paraffin and the surface. ${ }^{18}$ The deposits do not adhere to the metals themselves but are held in place by surface roughness. ${ }^{19}$ In this study, the mechanisms of wax deposition have been proposed to describe the formation of wax deposits on pipe walls. These mechanisms includes molecular diffusion, where wax start to deposit due to the diffusion of the dissolved molecules of the waxy components toward the pipe wall; shear dispersion mechanism illustrates the deposition of wax by the dispersion of the precipitated particles of the waxy components toward the pipe wall; Brownian diffusion mechanism describes wax deposition by the diffusion of the precipitated particles toward the wall; the diffusion of the precipitated particles is caused by Brownian motion; and gravity settling mechanism responsible for the wax deposition due to the settling of the precipitated particles of the waxy components toward the bottom of the pipe.

\section{Material and methods}

Many types of crude around the world contain dissolved waxes that can precipitate and deposit under the appropriate environmental conditions, leading to decrease production rates, equipment blockages, production shut down and creating other problems. Therefore, wax deposition must be mitigated in first place and must be removed when it already deposited. Wax deposition in crude oil production systems can be reduced or prevented by one or a combination of the mitigation methods such as chemical, mechanical and thermal mitigation methods. ${ }^{20}$ Wax deposition is highly impacted by temperature; therefore thermal methods can be applied to eliminate the problem. Thermal methods include heat retention, active heating and use of suitable exothermic chemical reactions. Thermal insulations, bottom whole heaters, hot oil circulation, steam circulation and on demand 'intervention' heating are appropriate for deep waters. Mechanically, Scrapers and cutters are used extensively to remove wax deposits from tubing because they can be economical and result in minimal formation damage. The mechanical removal method includes running scrappers in the borehole and pigging in pipelines at an intervention frequency. For deep waters, frequent intervention is not possible due to the long distance of the flow pipeline. With the advent of extremely deep production, offshore drilling and ocean floor completions, the use of the mechanical and thermal remediation methods has become economically prohibitive, as a result, the use of chemical additives as wax deposition inhibitors is becoming more prevalent ${ }^{12}$ due to the long distances covered by hydrocarbon flow lines; therefore, the chemical additives are the best solution for wax deposition in pipelines. To remove wax deposition chemically, solvents may be used to treat deposition in production strings and also may be applied to remediate formation damage. Chemical inhibitors have been used to reduce or prevent wax deposition in crude oil production. These inhibitors can be divided into four types: pour point depressants (PPD), crystal modifiers, dispersants and solvents.

\section{Discussion}

This section list and illustrates the main factors that affect and control the wax deposition process such as temperature differential and cooling rate, crude oil composition, experimental time, flow rate, pressure and pipe surface properties. Furthermore, describes the mechanisms that have been proposed to describe the formation of wax deposits on pipe walls, includes molecular diffusion, shear dispersion, Brownian diffusion and gravity settling.

\section{Factors affecting the wax deposition process}

Several factors affect and control the wax deposition process in pipelines, such as pipe wall temperature (inlet coolant temperature), crude oil composition, crude oil temperature, ambient temperature, flow rate, thermal history, time and pressure. ${ }^{21-28}$ Lab and field data shows that some of the most dominant factors in the deposition of waxes are:

\section{Temperature differential and cooling rate}

Wax deposition increases with an increase in the temperature difference between the bulk of the wax solution and the cold surface. 
Wax deposition will only occur when the surface temperature is below both the solution temperature and the solution cloud point. The impact of pipe wall cold surface (inlet coolant temperature) on wax deposition has been studied and reported in many recently-published papers, where it is considered as one of the main factors to affect wax deposition. ${ }^{27-29}$ The main conclusion in these works was that the inlet coolant temperature plays an important role in the wax deposition process; decreasing the inlet coolant temperature will increase the wax deposition, even when the crude oil temperature is above the wax appearance temperature. Initially, the rate of wax deposition is high, but it slows down as more wax is deposited on the pipe surface. The thickness of the wax layer increases and this layer acts as thermal insulation and reduces the effective temperature differential. This lowers the availability of wax crystals for further deposition. ${ }^{18}$ The size and number of crystals formed are also important for wax deposition. At a higher rate of cooling, the wax precipitates out of the oil in smaller crystals and a large number of crystals are formed because of the large number of crystallisation sites available. At a lower rate of cooling, the crystallisation process is more uniform. Thus, more uniformly packed crystals are formed that possess a relatively small surface area and free energy. The temperature differential also affects the composition of the deposited wax; if it is high, cooling is rapid and both lower and higher melting waxes crystallise simultaneously, forming a weak porous structure (owing to mal-crystallisation) with cavities full of oil. ${ }^{30}$

\section{Crude oil composition}

Stated ${ }^{11}$ that the crude oil composition is one of the main factors that significantly impacts wax deposition and is responsible for the pour point and viscosity reduction. The composition of crude oil comprises a mixture of molecules of different natures: there are light molecules like methane that are responsible for solid hydrate formation at high pressure and low temperature and heavy molecules such as long linear alkanes and isoparaffins that tend to change phase at low temperature in the phase of both macro and microcrystalline solids. There is also a transition towards more polar compounds due to the appearance of aromatic compounds and the presence of heteroatoms (oxygen, sulphur and nitrogen) in the fractions known as resins and asphaltenes ${ }^{31-34}$ mentioned in their literature review that the amount of deposited wax is impacted by the concentration of paraffin, light ends, and nucleating or inhibiting materials in the crude oil.

\section{Experimental time}

The experimental time is considered to be one of the important factors that influence wax deposition inside the pipelines. ${ }^{21-28}$ Wax deposition increased regularly during the first two hours of running the experiments in the lab rig because most of the dissolved paraffin in the crude oil was deposited on the pipe wall, but despite the reduction in the paraffin content in the crude oil, the wax deposit increased slightly with increasing experimental time. In the oil fields the wax deposition increases regularly due to more and more paraffin being deposited from the fresh crude oil on the hydrocarbon pipeline, providing a greater opportunity for deposition upon the cold surface. Lab rig studies have shown that a thermal pseudo-steady state is attained in less than 30 minutes during deposition from wax solvent mixtures under laminar and turbulent conditions. ${ }^{21-24}$ Laboratory studies have also shown a negligible increase in the mass of the deposit after 4 hours ${ }^{21}$ due to most of the wax molecules in the crude oil having been deposited on the pipe wall.

\section{Flow rate}

In laminar flow, wax deposition increases with decreasing flow rate. This can be explained by the availability of more particles for deposition at the surface. As the flow rate increases to turbulent regimes, wax deposition decreases because shear dispersion increases. Thus, wax deposition gradually decreases as turbulence and flow rate increases. Shear dispersion is predominant in turbulent flow in all stages. The flow behaviour in a flowing stream is described by the Reynolds number; above 2,000 this is often considered to be turbulent flow. The nature of the wax crystals is to adhere to the pipe surface with good cohesion among them; therefore, increasing the flow rate leads to breaking wax crystals up into smaller particles, reducing the rate of wax deposition and preventing it by minimising wax adhesion to the pipe wall. On the other hand, the wax that deposits at higher flow rates is harder and more compact due to only those wax crystals and crystal clusters being capable of firm attachment to the surface and these will not be removed from the deposit. ${ }^{35}$ Wax deposition is found to be problematic in low-flow-rate wells. Low flow rates generally affect wax deposition because of the longer residence time of the oil in the tubing. This increased residence time permits more heat loss and leads to a lower oil temperature, which in turn leads to wax precipitation and deposition. The minimum flow rate in the experimental rig to avoid deposition has been proposed to be $0.56 \mathrm{ft} /$ sec.

\section{Pressure}

The pressure drops during oil production from the reservoir to the surface facilities. Lighter hydrocarbons in the reservoir tend to be the first to leave the reservoir as the pressure falls; hence, the solubility of the wax is reduced. The WAT increases with the pressure above the bubble point pressure, for a constant composition. This phenomenon implies that an increase in the pressure in the singlephase liquid region (above the bubble point pressure) will aggravate wax deposition. The situation is different below the bubble point, where the oil has a two-phase constitution. The WAT decreases with an increase in the pressure up to the bubble point pressure owing to the dissolution of light hydrocarbon back into the liquid phase. Therefore, the dissolution of light hydrocarbons caused by variations in pressure directly affects wax deposition. ${ }^{34}$ Stated that pressure is not considered an important factor for wax deposition, especially for dead or stock tank oil; but despite this, it should not be neglected. The pressure helps to reduce the wax deposition due to increasing the solubility of the wax in crude oil.

\section{Pipe surface properties}

It is evident that during deposition, wax crystals adhere to the pipe surface; so wax deposition can also be a function of surface properties. As the paraffin wax is deposited on a surface, it is held in place by adsorption forces. These adsorption forces are dependent on the free surface energy of both the paraffin and the surface). The deposits do not adhere to the metals themselves but are held in place by surface roughness. ${ }^{19}$ There is no direct correlation between wax deposition and surface roughness. However, the adhesion bond at a surface should be proportional to the total contact area and therefore related to surface roughness. ${ }^{36}$ Wax molecules move toward via diffusion and adhere at the wall. The rate of adhesion is largely governed by the temperature difference between wall and fluid. ${ }^{26}$ Low friction internal pipe surfaces will also discourage deposition, if not precipitation, as 
wax crystals can only adhere to pipe walls if they have a sufficiently large coefficient of friction. The cohesive strength of sample wax deposits is of little consequence if they do not adhere well to the pipe wall. Field reports suggest that wax deposits' adhesive strength is at least equal to their cohesive strength and they cling tenaciously to the pipe wall. When casting pure macrocrystalline wax onto a steel pipe wall under laboratory conditions, however, this is not the case. The wax adheres so poorly to the steel that a negligible force is required to cause gross fracture at the steel/wax interface. If a wax model is to be found that can provide robust testing of removal concepts, it needs to allow cohesive failure of simulated deposits. That is, it needs to stick well to the pipe wall. ${ }^{26}$ It can be concluded that, at the very least reduced pipe diameter and increased surface roughness creates a larger pressure drop and reduced throughput; at the worst, wax deposits can be so severe that the pipe is blocked and production ceases completely.

\section{Wax deposition mechanisms}

Wax deposition is conceptually similar to other deposition mechanisms encountered in the engineering and medical fields, such as crystallisation fouling, frost formation and atherosclerosis. A number of mechanisms have been proposed to describe the formation of wax deposits on pipe walls. These mechanisms initially proposed by $^{37}$ and then by, ${ }^{9-14}$ includes molecular diffusion, shear dispersion, Brownian diffusion and gravity settling.

\section{Molecular diffusion}

For all flow conditions, oil will be in laminar flow, either throughout the pipe, or in a thin laminar sub-layer adjacent to the pipe wall. When the oil is being cooled, there is a temperature gradient across the laminar sub-layer. If the temperature is below the level where solid waxy crystals can be precipitated, then the flowing elements of oil will contain precipitated solid particles and the liquid phase will be in equilibrium with the solid phase; the liquid will be saturated with dissolved wax crystals. The temperature profile near the wall will lead to a concentration gradient of dissolved wax, and this dissolved material will be transported toward the wall by molecular diffusion. When this diffusing material reaches the solid/liquid interface, it will be precipitated out of solution. Reported that there are two stages involved in wax deposition: wax gel formation and then the aging of the deposited wax gel. Petroleum wax deposits contain some entrapped crude oil, water, gums, resins, sand and asphaltenes, depending on the nature of the particular crude oil. The trapped oil in the wax deposit causes diffusion of wax molecules into the gel deposit and counter-diffusion of oil out of the gel deposit, as shown in Figure 2. A fraction of hydrocarbons with carbon numbers above a certain value (the critical carbon number) precipitate out of the oil as stable crystals to form a gel with the remaining hydrocarbons trapped in the gel network. In the gel deposit, the fraction of molecules with carbon numbers greater than the critical carbon number increases, while that of molecules with carbon numbers lower than the critical carbon number decreases. The diffusion and counter-diffusion, leading to hardening of the gel deposit, increases the size of the deposit, and increases the amount of wax in the gel deposit; this process is called aging, the second stage of wax deposition. Molecular diffusion is therefore critical to the aging and hardening of wax gel deposits. ${ }^{38}$

\section{Molecular diffusion equation}

As discussed, precipitation of wax occurs at contact points between the dissolved wax solution and the cool wall surface. The experiment by ${ }^{37}$ confirmed that molecular diffusion dominates as the primary mechanism at high temperature heat flux conditions typical of subsea flow line systems. They showed that Fick's law of diffusion can model molecular diffusion of solid wax in oil and gas flows. Thus, the rate of wax deposition can be described by the following equation:

$$
\frac{d M_{w}}{d t}=\rho_{w} D_{w} A_{w} \frac{d C}{d r}=\rho_{w} D_{w} A_{w} \frac{d C}{d T} \frac{d T}{d r} \rightarrow
$$

Where $d M w / d t$ is the rate of wax deposited $(\mathrm{kg} / \mathrm{s}), \rho w$ is the density of the solid wax $\left(\mathrm{kg} / \mathrm{m}^{3}\right), D w$ is the diffusion coefficient of the wax in the oil phase $\left(\mathrm{m}^{2} / \mathrm{s}\right), A w$ is the area of wax deposition $\left(\mathrm{m}^{2}\right), d C /$ $d r$ is the wax concentration gradient $(1 / \mathrm{m})$ of wax concentration over pipe radial coordinate $r(\mathrm{~m}), d C / d T$ is the solubility coefficient of the wax crystal in the oil phase $\left(1 /{ }^{\circ} \mathrm{C}\right)$ and $d T / d r$ is the radial temperature gradient of the wall $\left({ }^{\circ} \mathrm{C} / \mathrm{m}\right)$. The diffusion coefficient can be described as follows:

$$
D_{w}=7.4 \times 10^{-9} \frac{T_{a}(\xi M)^{0.5}}{\mu V^{0.6}} \rightarrow
$$

Where $T a$ is the absolute temperature $(\mathrm{K}), M$ is the molecular weight of the oil solvent $(\mathrm{g} / \mathrm{mol}), V$ is the wax molar volume $(\mathrm{cc} / \mathrm{g}$ mole), $\mu$ is the dynamic viscosity (cP) and $\xi$ is an association parameter representing the effective molecular weight of the solvent with respect to molecular diffusion and $V^{0.6}$ is proportional to the absolute temperature $T a$. The association parameter $\xi$ and the molecular weight of the oil solvent $M$ are constants in the equation. The diffusion coefficient in principle is proposed as a function of oil constant $C 1$ and oil viscosity in many diffusion coefficient models.

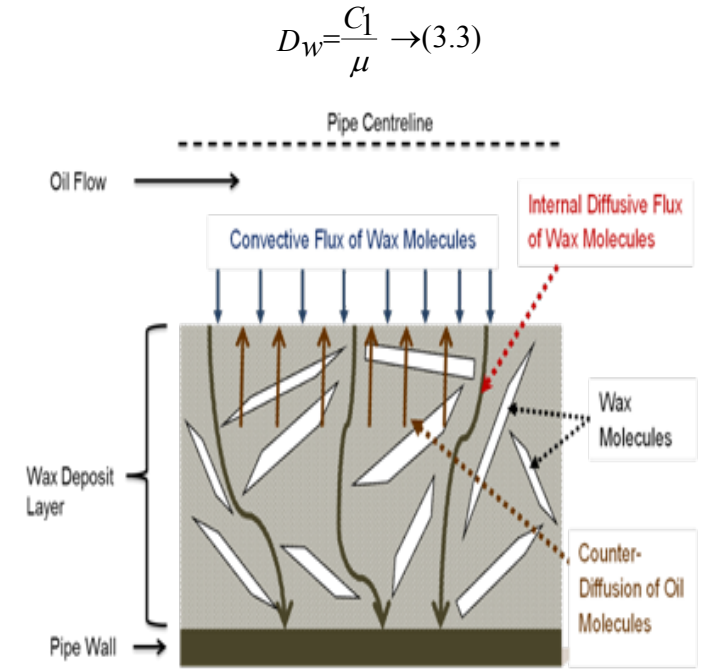

Figure 2 Illustration of how wax molecules diffuse to form the wax deposit layey. ${ }^{38}$

As temperature decreases in the radial direction of the pipe, the viscosity of the oil can increase and the diffusion coefficient of the wax in oil can decrease substantially. ${ }^{9}$ It can therefore be concluded that molecular diffusion is considered as the main mechanism for wax deposition due to the diffusion of the dissolved molecules of the waxy components toward the wall; this has also been used by many wax modelling studies. 


\section{Shear dispersion}

When small particles are suspended in a fluid that is in laminar motion, the particles tend to move at the mean speed and in the direction of the surrounding fluid. The particle speed is that of the streamline at its centre, and the particle rotates with an angular velocity that is half the fluid shear rate, as shown in Figure $3 .^{39}$ If the particles approach a solid boundary, both linear and angular velocities will be reduced. Due to the fluid viscosity, rotating particles will impart a circulatory motion onto a layer of fluid adjacent to the particle. This rotating fluid region exerts a drag force on neighbouring particles. In a shear field, each particle passes and interacts with nearby particles in slower or faster moving streamlines. When only two particles are present, far from a wall and at a very low Reynolds number, these passing encounters result in large temporary displacements. As the particles pass, their trajectories are such that the particles curve around one another and return to their original streamline; thus, there is no net lateral displacement. If the particle concentration is high, however, then a significant number of multi-particle interactions will occur. These multi-particle collisions result in net lateral transport and dispersion of particles. Shear dispersion can be modelled by the

dispersion coefficient of: ${ }^{37} D_{S}=\gamma \frac{d 2 \varphi_{w}}{10} \rightarrow(3.4)$

Where $\gamma$ is the oil shear rate at the pipe wall $(1 / \mathrm{s}), \varphi_{w}$ is the wax particle diameter $(\mathrm{m}), \varphi_{w}$ is the wax volume fraction out of the solution at the wall and $D_{S}$ is the shear dispersion coefficient $\left(\mathrm{m}^{2} / \mathrm{s}\right)$.

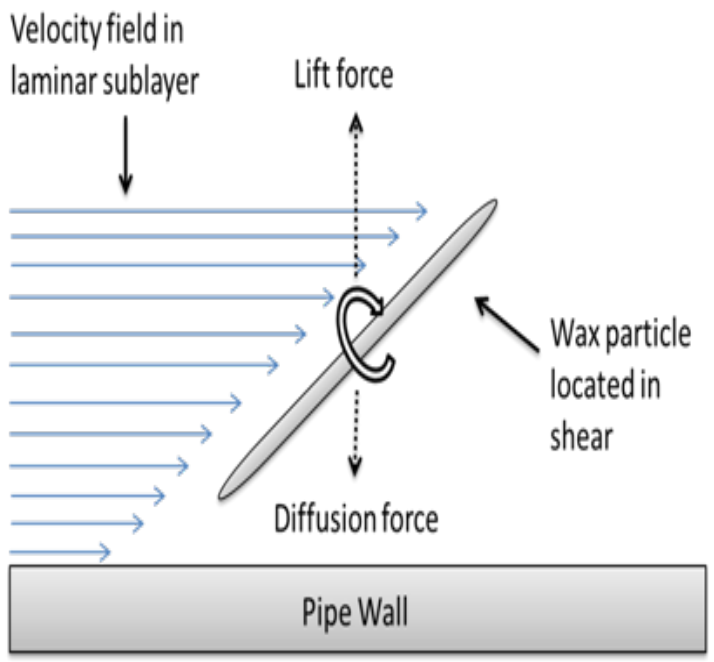

Figure 3 Long wax particle located in shear flow. ${ }^{39}$

\section{Brownian diffusion}

When suspended in oil small waxy crystals will be continually bombarded by thermally agitated oil molecules. These collisions will lead to small random Brownian movements of the suspended particles. If there is a concentration gradient of these particles, the Brownian motion will lead to a net transport, which in nature and mathematical description is similar to diffusion. Agitated oil molecules bombard precipitated wax suspended in waxy-oil flows. This creates a net irregular movement of wax particles. ${ }^{37}$ If concentration gradients exist for the wax solid, a net transport of the precipitated molecules is initiated in the direction of decreasing concentration modelled by Fick's law of diffusion. ${ }^{40}$

$$
\frac{d M_{B}}{d t}=\rho_{w} D_{B} A_{w} \frac{d C}{d r} \rightarrow(3.5)
$$

Where $M_{B}$ is the mass of deposited wax due to Brownian diffusion (kg), $\frac{d C}{d r}$ is the concentration gradient over the pipe radial coordinate $(1 / \mathrm{m}), A_{\mathcal{W}}$ is the area of wax deposition $\left(\mathrm{m}^{2}\right)$ and $D_{B}$ is the Brownian diffusion coefficient $\left(\mathrm{m}^{2} / \mathrm{s}\right)$ derived by the following equation: ${ }^{37-40}$

$$
D_{B}=\frac{R T}{6 \pi \mu a N} \rightarrow(3.6)
$$

$R$ is the gas constant $\left(\mathrm{J} /(\mathrm{mol} . \mathrm{K}), T_{a}\right.$ is the absolute temperature (K), $\mu$ is the oil viscosity $\left(\mathrm{Ns} / \mathrm{m}^{2}\right), a$ is the Brownian particle diameter (m) and $N$ is Avogadro's number $(1 / \mathrm{mol})$.

\section{Gravity settling}

Precipitated waxy crystals are denser than the surrounding liquid oil phase. Hence, if particles are non-interacting, they will settle in a gravity field and can be deposited on the bottom of pipes or tanks. For an initially uniform mixture in a vessel, there will be a beginning rate of settling, followed by a diminishing rate of deposition, which will asymptotically approach zero at complete settling. In a typically active system, as found in oil and gas pipelines, gravity settling has been found to be negligible as the suggested shear dispersion mechanism or active fluid forces create dispersion of precipitated wax particles, thereby eliminating gravity settling. ${ }^{37-40}$ However, in low flow rates, at typical shut-in conditions or in storage tanks, the gravity effect is expected to contribute to significant wax deposition particularly observed for low viscous fluids. The settling velocity $U(\mathrm{~m} / \mathrm{s})$ is given by the modified Stokes' law of settling crystals in a pseudoplastic fluid as follows: ${ }^{41}$

$$
\mathrm{U}=\left[\frac{g \Delta P a^{(1+n)}}{18 K p}\right]^{1 / n} \rightarrow(3.7)
$$

Where $\Delta P$ is the density difference $\left(\mathrm{kg} / \mathrm{m}^{3}\right)$ between the settling wax and the oil, $a$ is the particle diameter $(\mathrm{m}), n$ the power-law index, $g$ the acceleration due to gravity $(\mathrm{m} / \mathrm{s} 2)$ and $K p$ is the power-law consistency index. The shear rate and shear stress relationship of a

power law fluid implied in the correlation is given to be: $\tau=K p \gamma^{n}$ where $\tau$ is the shear stress $\left(\mathrm{N} / \mathrm{m}^{2}\right)$ and $\gamma$ is the shear rate of the fluid $(1 / \mathrm{s}){ }^{37}$ The other three mechanisms-Brownian diffusion, gravity settling and shear dispersion-are considered, according to the work of researchers, ${ }^{28-35}$ as secondary mechanisms that can contribute to the wax deposition and identifying which mechanism plays the primary role in wax deposition stated that the Brownian diffusion of wax particles is not likely to be valid because the wall temperature is lower than the oil bulk temperature, resulting in more precipitated wax particles at the wall than in the bulk oil. Consequently, the impact of Brownian diffusion is to transport these precipitated particles from the wall toward the bulk oil, instead of moving them toward the wall and deposit ${ }^{42}$ noted that gravity settling is also believed to be insignificant as there has not been a study claiming that wax deposits are generally 
thicker at the bottom than the top of the pipe wall in single-phase oil flow conditions. The mechanism of shear dispersion was studied by, ${ }^{43}$ they found that the wax deposition rate did not increase with the increasing shear rate of the fluid, casting the first doubt on this mechanism for wax deposition..$^{44-47}$

\section{Conclusion}

Wax deposition on the hydrocarbon pipelines of the cold environment considers as one of the main fluid flow assurance challenges that face the petroleum engineers. Wax can precipitate as a solid phase on the pipe wall when its temperature drops below wax appearance temperature. It results in the restriction of crude oil flow in the pipeline, creating pressure abnormalities and causing an artificial blockage leading to a reduction or interruption in the production. Different wax deposition mechanisms, factors affecting wax deposition problem were reported. Also, were mentioned the wax mitigation methods. In the worst cases, when no of such methods is feasible to be used, production must be stopped in order to cut and replace the plugged portion of the line.

\section{Acknowledgement}

None.

\section{Conflict of interest}

The author declare that they have no conflict of interest.

\section{References}

1. Venkatesan R, Creek JL. Wax Deposition during Production Operations: SOTA, SPE, Chevron Energy Technology Co., Offshore Technology Conference, Texas, USA; 2007.

2. Tordal A. Pigging Of Pipelines with High Wax Content. Publication of Pigging Products and Services Association, Statoil ASA, Stavanger, Norway; 2006.

3. Zhu T, Walker JA, Liang J. Evaluation of Wax Deposition and Its Control during Production of Alaska North Slope Oils. Final Report, University of Alaska Fairbanks, ConocoPhillips Alaska, Inc: University of Kansas, United States Department of Energy National Energy Technology Laboratory, Oil \& Natural Gas Technology, DOE Award No: DE-FC26-01NT41248. 2008. 296 p.

4. Time RW. Flow Assurance and Multiphase Flow (Part II). The University of Stavanger, Department of Petroleum Engineering, Seminar Presented at Aker Solutions, Stavanger; 2011.

5. Dantas Neto AA, Gomes EAS, Barros Neto EL, et al. Determination of Wax Appearance Temperature (WAT) in Paraffin/Solvent Systems by Photoelectric Signal and Viscosimetery. Brazilian Journal of Petroleum and Gas. 2009;3(4):149-157.

6. Lee HS. Computational and Rheological Study of Wax Deposition and Gelation in Subsea Pipelines. PhD Thesis, University of Michigan; 2008 .

7. Botne KK. Modelling wax thickness in single-phase turbulent flow. MSc thesis, Norwegian University of Science and Technology, Department of Petroleum Engineering and Applied Geophysics; 2012.

8. Theyab MA, Diaz P. An Experimental and Simulation Study of Wax Deposition in Hydrocarbon Pipeline. Global Journal of Engineering Science and Researches. 2017;4(7):27-40.

9. Huang Z, Zheng S, Fogler HS. Wax Deposition: Experimental Characterizations, Theoretical Modeling, and Field Practices. USA Taylor \& Francis Group; 2015.
10. Singh P, Venkatesan R, Fogler HS, et al. Formation and aging of incipient thin film wax-oil gels. AIChE. 2000;46(5):1059-1074.

11. Singhal HK, Sahai GC, Pundeer GS, et al. Designing and Selecting Wax Crystal Modifier for Optimum Field Performance Based on Crude Oil Composition, 66th Annual Technical Conference and Exhibition, Dallas, Texas, USA; 1991.

12. Adeyanju OA, Oyekunle LO. Experimental Study of Wax Deposition in a Single Phase Sub-cooled Oil Pipelines, in: The Nigeria Annual International Conference and Exhibition, University of Lagos, Nigeria; 2013;1-18.

13. Dwivedi P, Sarica C, Chang W. Experimental Study of Wax deposition Characteristics of a Waxy Crude oil under Single Phase Turbulent Flow Conditions. Society of Petroleum Engineers Journal. 2012;61-73.

14. Han S, Huang Z, Senra M, et al. Method to determine the wax solubility curve in crude oil from centrifugation and high temperature gas chromatography measurements. Energy \& Fuels. 2010;24(3):17531761 .

15. Abdel Waly AA. The factors affecting paraffin deposition in oil wells. Journal of Engineering and Applied Science. 1999;46:381-386.

16. Hoffman R, Amundsen L. Single-Phase Wax Deposition Experiments. Energy \& Fuels. 2010;24(2):1069-1080.

17. Venkatesan R. The Deposition and Rheology of Organic Gels, Doctoral Thesis in Chemical Engineering, the University of Michigan; 2014. 225 p.

18. Misra S, Baruah S, Singh K. Paraffin Problems in Crude Oil Production and Transportation: A Review, SPE, Oil \& Natural Gas Corp, Ltd; 1995.

19. Jonathan, Southgate. Wax removal using pipeline pigs, Durham theses, Durham University; 2004.

20. Woo GT, Garbis SJ, Gray TC. Long-Term Control of Paraffin Deposition, SPE Annual Technical Conference and Exhibition, Houston; 1984:1619.

21. Kasumu AS. An Investigation of Solids Deposition from Two-Phase Wax-Solvent-Water Mixtures. PhD Thesis, Galgary University; 2014.

22. Noville I, Naveira, L. Comparison between Real Field Data and the Results of Wax Deposition Simulation," SPE 152575 presented at SPE Latin American and Caribbean Petroleum Eng Conf, Mexico; 2012.

23. Leontaritis KJ, Geroulis E, Wax Deposition Correlation-Application in Multiphase Wax Deposition Models, Asph Wax, Inc: Offshore Technology Conference, Texas, USA; 2011.

24. Tiwary R, Mehrotra AK. Deposition from wax-solvent mixtures under turbulent flow: effects of shear rate and time on deposit properties. Energy Fuels. 2009;23(3):1299-1310.

25. Solaimany Nazar AR, Dabir B, Islam MR. Experimental and mathematical modeling of wax deposition and propagation in pipes transporting crude oil. Energy Sour. 2005;27(1-2):185-207.

26. Singh P, Venkatesan R, Fogler HS, et al. Morphological evolution of thick wax deposits during aging. AIChE. 2001;47(1):6-18.

27. Creek JL, Lund HJ, Brill JP, et al. Wax deposition in single phase flow. Fluid Phase Equilibria Journal. 1999;158(160):801-811.

28. Hammami A, Raines MA. Paraffin deposition from crude oils: comparison of laboratory results with field data. Society of Petroleum Engineers Journal. 1999;4:9-18.

29. Leontaritis KJ. Wax Flow Assurance Issues in Gas Condensate Multiphase Flowlines, Offshore Technology Conference, Houston, Texas, USA; 2017. 
30. Kang PS, Lee DG, Lim JS. Status of Wax Mitigation Technologies in Offshore Oil Production, in: International Society of Offshore and Polar Engineers Conference, Busan, Korea, 2014;15-20:31-38.

31. Merino-Garcia D, Duenas-Diez M, Gomez S, et al. Risk Assessment Methodology for Flow Assurance Challenges: The Sooner You Look at It, the Better, Offshore Technology Conference Paper 22404; 2013.

32. Zerpa LE, Sloan ED, Koh CA, et al. Hydrate Risk Assessment and Restart Procedure Optimization Offshore Using a Transient Hydrate Prediction Model, Offshore Technology Conference Paper 22406, Brazil; 2011

33. Merino-Garcia D, Shaw J, Carrier H, et al. Petrophase 2009 Panel Discussion on Standardization of Petroleum Fractions. Energy and Fuels. 2010;24(4):2175-2177.

34. Valinejad R, Solaimany Nazar AR. An experimental design approach for investigating the effects of operating factors on the wax deposition in pipelines. Fuel Journal. 2013;106:843-850.

35. Bott TR, Gudmunsson JS. Deposition of Paraffin Wax from Kerosene in Cooled Heat Exchanger Tubes. Canadian Journal of Chemical Engineering. 1977;55(4):381-385.

36. Patton CC, Casad BM, Paraffin Deposition from Refined Wax Solvent System, SPEJ; 1970. 17 p.

37. Burger ED, PerkinsTK, Striegler JH. Studies of Wax Deposition in the Trans Alaska Pipeline. SPE Journal of Petroleum Technology. 1981;33(6):1075-1086

38. Theyab MA, Diaz P. Experimental Study on the Effect of Spiral Flow on Wax Deposition Thickness, One petro, presented at SPE Russian Petroleum Technology Conference and Exhibition, Moscow, Russia; 2016b. p. 24-26.
39. Siljuberg MK. Modelling of Paraffin Wax in Oil Pipelines, NTNUTrondheim; 2012

40. Azevedo LFA, Teixeira AM. A Critical Review of the Modeling of Wax Deposition Mechanisms. Petroleum Science and Technology. 2003;21(3-4):393-408.

41. Ajayi OE. Modelling of controlled wax deposition and loosening in oil and gas production systems. MSc Thesis, Norwegian University of Science and Technology NTNU; 2013. 106 p.

42. Hsu JJC, Santamaria MM, Brubaker JP, et al. Wax Deposition And Gel Strength Of Waxy Live Crudes, in: Offshore Technology Conference, Texas, USA, 1994;2(5):555-562.

43. Bern PA, Withers VR, Cairns JR. Wax deposition in crude oil pipelines, in: Proc European Offshore Petroleum Conference and Exhibition, London, England, 1981. p. 21-24.

44. Han S, Song Y, Ren T. Impact of Alkyl Methacrylate-Maleic Anhydride Copolymers as Pour Point Depressant on Crystallization Behaviour of Diesel Fuel. Energy and Fuel. 2009;23(5):2576-2580.

45. Kasumu AS, Mehrotra AK. Solids deposition from two-phase waxsolvent-water "waxy" mixtures under turbulent flow. Energy \& Fuels. 2013;27(4):1914-1925.

46. Theyab MA, Diaz P. Experimental Study on the Effect of Spiral Flow on Wax Deposition Volume, One petro, presented at Abu Dhabi International Petroleum Exhibition and Conference, Abu Dhabi, UAE; 2016 a.

47. Theyab MA, Diaz P. Experimental Study of Wax Deposition in Pipeline - Effect of Inhibitor and Spiral Flow. International Journal of Smart Grid and Clean Energy. 2016c;5(3):174-181. 